\title{
InícIo OU O Colnpso do inferno?
}

\author{
Igor de Souza Rodrigues ${ }^{7}$
}

\section{RESUMO}

Este trabalho tem como objetivo abordar a criação do primeiro complexo penitenciário do Brasil construído e administrado por empresas particulares, 0 Complexo Penitenciário Ribeirão das Neves, instituído no estado de Minas Gerais. Enquanto tal, atesta para a vital necessidade de se contextualizar a discussão em meio a mudanças ocorridas, principalmente, na segunda metade do Século XX, onde o estado de bem-estar social vai, aos poucos, cedendo lugar ao estado penal. Assim, busca-se fazer uma análise crítica da forma liberal e conservadora com o qual o tema é tratado, na expressão em nível ótimo "a cadeia é um inferno", não para diminuir o estado penal, mas justamente ao contrário, para aumentá-lo.

Palavras-chave: Prisões privada. Neoliberalismo. "Mercantilização" da segurança. Estado penal.

\section{ABSTRACT}

This work aims to address the creation of Brazil's first prison complex built and run by private companies, the Penitentiary Ribeirão das Neves, instituted in the state of Minas Gerais. As such, attests to the vital need to contextualize the discussion in the midst of changes, especially in the second half of the twentieth century, where the state of Social Welfare will gradually giving way to the state prosecution. Thus, it seeks to make a critical analysis of liberal and conservative manner with which the subject is treated in the optimal expression "jail is hell", not to diminish the criminal state, but just the opposite, to enlarge it.

Keywords: Private Prisons. Neoliberalism. "Commodification" of safety. Criminal State.

\section{INTRODUÇÃO}

Há rios de tinta retratando a prisão brasileira como um filme de terror, um verdadeiro inferno, como faz Luiz Francisco Carvalho Filho (2002). Nesse tipo de

7 Mestrando e bolsista Capes - DS pelo Programa da Pós-Graduação em Ciências Sociais da Universidade Federal de Juiz de Fora (2013); Advogado, graduado em Direito pelo Instituto Vianna Júnior (2008-2013); Graduado em Ciências Sociais pela Universidade Federal de Juiz de Fora (2009-2013); Editor-chefe da Revista Eletrônica Investidura (2012-2013), tem experiência na área de criminologia, com ênfase em processos de rotulação e estigma. 
pensamento "o inferno não é embaixo da terra; o inferno é o presídio". O problema que gostaríamos de chamar atenção não está na representação em si da prisão como um inferno, mas em suas consequências conservadoras que aparecem quando essa contestação serve como argumento "pseudo-humanitário" [e, portanto, mais difícil de ser enxergado e combatido] para afirmá-la enquanto uma instituição essencial ao controle $^{8}$ e na repressão dos grupos considerados perigosos e perturbadores.

O discurso mais constantemente repetido nos jornais e mesmo no debate intelectual brasileiro reclama pouca vigilância, controle, precariedade das condições estruturais, ociosidade e regalia dada aos presos, entre outras coisas, sobretudo, como sustentáculo de um discurso mais punitivo, de um estado "menos social e mais repressivo". É o que se oberva, por exemplo, em uma reportagem publicada pela Revista Veja que divulgou com destaque a experiência do primeiro complexo penitenciário Brasil construído e administrado por empresas particulares, proposto pelo ex-governador do estado de Minas Gerais e então senador da República Aécio Neves, e pelo seu sucessor ao governo do estado Antônio Anastasia, construído na cidade de Ribeirão das Neves, região metropolitana de Belo Horizonte. No artigo, intitulado "É exceção, mas deveria ser regra" o complexo prisional é tido como "exemplo a ser seguido" e "um primor".

$\mathrm{Na}$ solenidade de inauguração do complexo prisional, o senador Aécio Neves comentou que o processo se iniciou há alguns anos, quando ainda era governador do estado. Segundo ele, muitos não acreditavam na possibilidade de o setor privado participar desse esforço e foram radicalmente contrários. "Nós estamos aqui dando uma importante contribuição para que o Brasil vire a página daquilo que o ministro da Justiça chamou de cadeias medievais como regra hoje para as cadeias públicas, para as penitenciárias públicas."

Diante disso, o objetivo é discutir este "novo modelo prisional", enquanto algo inserido em uma dimensão maior: o controle como instrumento político e a

8 Por controle, Stanley Cohen, entende, "um conjunto de meios pelos quais uma sociedade responde aos indivíduos ou grupos sociais que, de alguma maneira, colocam em risco a ordem estabelecida." (COHEN apud DORNELLES, 2003, p. 21) 
relação entre a assimetria de poder e o controle, cuja dimensão é atravessada pela invisível luta de classes no Brasil. Discutir tal problema implica pensar principalmente nas mudanças sofridas na segunda metade do Século XX: o engendro do neoliberalismo, de novas tecnologias e de um estado menos social e mais penal.

Não é a primeira vez que tratamos dos temas quem envolvem essa discussão. No ano de 2011, ainda durante a graduação do curso de sociologia na Universidade Federal de Juiz de Fora, começamos a nos interessar por temas como o crime, drogas, desvio, rótulos, estigma e identidades sociais. Tanto é assim, que buscamos levar um pouco de sociologia ao direito, curso que fazíamos paralelamente. Na monografia do curso de direito discutimos a dinâmica de forças da rotulação, buscando entender como essa força é formada e como ela opera. Interessados pelo assunto, no ano de 2012, em um trabalho intitulado " $A$ rua por seu morador", orientado pela professora Beatriz de Basto Teixeira, do departamento de sociologia da Universidade Federal de Juiz de Fora, estudamos a socialização do morador de rua e a interação com o espaço urbano - como a noção de segurança e do medo, por exemplo, estavam atreladas à exposição e a visibilidade que o morador de rua estava submetido, principalmente enquanto dormia. Em seguida, na monografia do curso de sociologia, intitulada "O ser bandido", orientada pelo professor Jessé Souza, abordamos a relação identidade e controle social, isto é, como o "ser bandido" não é um indivíduo que praticou crimes, mas uma identidade social representada enquanto tal.

A construção teórica e metodológica está envolta dessas experiências anteriores, mas, em termos inaugurais, discutiremos o primeiro complexo penitenciário do Brasil construído e administrado por empresas particulares, proposto como um "novo modelo prisional inspirado no inglês", dentro de uma perspectiva crítica e contextualizada, que não o trate como algo descolado da vida social e dos pressupostos que o animam.

É uma questão relevante dada à tendência crescente de implementação deste tipo particular de prisão e, mais do que isso, de gestão de parte do controle 
penal. Segundo Julita Lemgruber, em entrevista ao Jornal Brasil de Fato, publicada no dia 05 de fevereiro de 2013, nós vamos enfrentar um tsunami. Isso vai invadir o país. São Paulo vai entrar para esse caminho. Pernambuco já entrou, Ceará já entrou, tem vários estados já. Lemgruber afirma que a curto-prazo é muito atraente, mas implica numa série de problemas em longo prazo.

A forma que abordaremos a criação do presídio em questão não se restringe a seu modelo de funcionamento, embora esse fator tenha grande relevância na análise e esteja contido na discussão. O ponto principal é entender como e porque a o crime e a violência são tratados como problema de segurança e não qualquer outro, e porque a segurança pública tem sido demonizada com intento de seu aumento, transformando, ideologicamente, interesses particulares em interesses gerais.

\section{COMPLEXO PRISONAL RIBEIRÃO DAS NEVES}

O Complexo Penitenciário Ribeirão das Neves entrou em funcionamento dia 18 de janeiro de 2013, na Região Metropolitana de Minas Gerais. Ribeirão das Neves tem cerca de 300 mil habitantes e sua população tem grande vínculo com a capital Belo Horizonte, dado à proximidade das cidades. Atualmente a cidade tem mais de 5 mil presos, Ribeirão das Neves abriga $10 \%$ de toda a população carcerária do estado de Minas Gerais (51.958 encarcerados de acordo com dados do Infopen, do Ministério da Justiça (ref. 12/2012). No entanto, com a chegada de mais presos para o novo complexo, esse número aumentará significativamente. Esta é a sexta unidade prisional do município. Sem contarmos o aumento populacional com chegada da família dos presos,e outras pessoas que chegam na cidade.

O Grupo ganhador da licitação, Gestores Prisionais Associados (GPA: CCl Construções, Construtora Augusto Velloso, Empresa Tejofran de Saneamento e Serviços Ltda., N.F Motta Construções e Comércio e Instituto Nacional de Administração Prisional), é responsável pela construção e gestão da penitenciária 
e se dispôs ao investimento de 280 milhões de reais; em contrapartida o estado paga ao consórcio administrador um valor por detento, que varia de acordo com o cumprimento das metas, em média, 2.100 reais por preso, a cada mês, nos próximos 27 anos. $O$ grupo gestor terá de cumprir um conjunto de 380 indicadores de desempenho definidos pelo governo do estado, dentre eles metas para impedimentos de fugas, motins ou rebeliões. Caso algum dos indicadores não atinja o objetivo, há desconto no repasse de verbas previsto.

Três grupos de servidores ficam responsáveis pela segurança e movimentação dos presos. Um deles vai agir em situações de conflito dentro das unidades, disponível 24 horas, outro será responsável por atividades de segurança (externa, muralhas, portaria, escoltas dos sentenciados e intervenção em caso de necessidade) e o terceiro cuidará do monitoramento interno dos detentos.

\section{MUDANÇAS SOCIAIS}

O controle social e os instrumentos de controle, inclusive a prisão, sofreram grandes mudanças a partir do pós-guerra. Houve uma "virada histórica no controle do crime" (GARLAND, 2008, p.182), "uma reconstrução de todo o campo do controle" (idem), decorrentes da alteração na dinâmica da produção capitalista e das trocas mercantis e os correspondentes avanços tecnológicos, da reestruturação da família, de mudanças no espaço urbano e na configuração das cidades, do crescimento das mídias de massa e meios eletrônicos.

Esse processo de mudança não pode ser tomado como mera "coincidência" ou uma "configuração aleatória", ele está contido dentro da própria transformação da vida social. Entender como esse processo está associado a um conjunto de variações econômicas, políticas e sociais: "uma combinação do 'neoliberalismo' - de livre mercado com conservadorismo social" (GARLAND, 2008) - se faz importante para compreender essa nova ordem do controle, inclusive da prisão. 
A constituição do estado previdencialista se deu principalmente com os problemas sociais advindos da Primeira Guerra Mundial e da Grande Depressão. O Estado americano, por exemplo, que vinha adotando políticas liberais, viu-se obrigado a conter a desregulação do mercado e intervir na economia. Franklin Roosevelt lançou o plano New Deal, investimentos, principalmente públicos, e medidas visando minimizar os efeitos da crise que assolava todo país. No Brasil, apesar da inexistência de um típico Estado de bem-estar social, houve, a partir dos anos 30 , sobretudo no primeiro mandato do presidente Getúlio Vargas, políticas sociais atinentes e coadunantes com as do welfare state, que impossibilitam pensar o Brasil como uma exceção a este contexto.

Décadas mais tarde, com a crise do petróleo, as políticas previdenciárias destinadas aos pobres e excluídos foram paulatinamente sendo "consideradas luxos onerosos" (GARLAND, 2008, p. 182). As políticas dos anos 80 em diante foram pensadas não mais a partir do previdencialismo, muito pelo contrário, entendia-se que os problemas não só não foram solucionados por este, mas criados pelo estado de bem-estar social. A reação contra o previdencialismo penal assumiu uma forma "reacionária" totalizante, porque, subjacente ao debate sobre o crime e a pena, houve uma mutação fundamental nos interesses e sensibilidades (GARLAND, 2009, p. 182). Ou seja, a mudança nos interesses e na sensibilidade das classes, em grande parte foi uma resposta à crise do estado de bem-estar social.

É também da década de oitenta em diante que o crime e a violência passam a ser entendidos, sobretudo, como um problema de segurança e não mais social. Nesta toada, nascem às raízes da política de tolerância zero, modelo de política de segurança na vitrine americana florescido no ano de 1993. [A implementação da política de tolerância zero tem correlação direta com a criminalização de uma população marginalizada, isto é, de uma população precariamente inserida no mercado de trabalho ou, quando pior, sequer inserida]. Conforme Wacquant (1999, p 19), a doutrina da tolerância zero apareceu como instrumento de legitimação da gestão policial e judiciária da pobreza que 
incomoda, como moradores de rua, mendigos, pequenos ladrões, pichadores e usuários de drogas - que eram tidos como causa de incidentes e desordens no espaço público, alimentando uma profunda sensação de insegurança, incomodo.

João Ricardo Dornelles, em "Conflito e segurança (entre pombos e falcões)", também fez observações acerca destas mudanças e ressalta a importância de se alinhavar os estudos do crime e do controle a tais perspectivas. Segundo ele, o programa neoliberal, nos últimos trinta anos, ocasionou a marginalização e exclusão social crescente, com características estruturais. Antes disso, a exclusão social em larga escala era um fenômeno conjuntural que se expandia nas crises cíclicas do sistema capitalista. Outro ponto é a debilitação dos direitos econômicos, sociais e culturais, principalmente dos direitos coletivos da classe trabalhadora, a partir da ofensiva do capital e levando à flexibilização e precarização das relações de trabalho (DORNELLES, 2003, p.27). Garland, no mesmo sentido, defende que o emprego sofreu transformações e se tornou cada vez mais precário. $O$ trabalhador, principalmente, a mão de obra desqualificada, se tornou mais flexível e disposto a aceitar salários mais baixos e condições impostas. (GARLAND, op. cit., p.191)

\subsection{A PRISÃO E A DESIGUALDADE SOCIAL}

A parceria público privada para a administração do presídio, como o Ribeirão das Neves, está inserida dentro deste processo social. Não como causa, mas consequência, em primeiro da demonização da figura do estado de bem-estar social, "ineficiente", "burocrata", o reino da corrupção - como se o mercado fosse o campo da virtude, o que, na verdade, opera como cortina ideológica para mascarar os interesses liberais, como Jessé Souza demonstrou em a "Ralé Brasileira: quem é e como vive" (2009). [Liberal não só no sentido de transferir a prisão do público para o privado, mas de engendrar uma ordem social punitiva em desfavor de classes consideradas "perturbadoras" e "ameaçadoras" aos condomínios de luxo, shoppings, praças, etc.]. Em segundo, em tratar o problema 
do crime, especificamente como uma questão de segurança e controle, de um estado "mais penal".

No campo do crime e todos os seus correlacionados [vigilância, controle, punição], há forte influência das notícias dos "tabloides" e de uma verdadeira "ficção televisiva" na formação do senso comum. Ocorre que, no Brasil, os jornais e as revistas mais importantes adotam uma perspectiva liberal conservadora do crime e da criminalidade que, ao mesmo tempo, centraliza o poder no estado, o demoniza, invocando um discurso meritocrático que faz desaparecer a seletividade do controle penal, como se não houvesse um componente de segmentação social que o torna mais áspero e punitivo justamente onde o estado é "menos social". A cadeia passa, então, a ser vista como o destino para criminosos indisciplinados, seres "antissociais" e "não tão humanos ou dignos de humanidade".

Rodrigo Constantino, colunista da revista Veja, autor do livro "Privatize Já", diz, em uma coluna intitulada "Prisão privada", que o governo brasileiro é tão agigantado e seu escopo de ação é tão extenso que ele acaba não fazendo direito nem mesmo aquilo que deveria ser sua função. Assim sendo, restaria privatizar áreas que outrora talvez nem precisassem ser privatizadas, e continuar lutando para que o governo reduza seu campo de ação, para ter mais foco naquilo que realmente é importante e de sua seara. Constantino, embora um "liberal assumido" - como ele próprio se concebe - faz uma distinção ingênua entre o bem e o mal; entre estado e mercado, como se o estado fosse o campo da ineficiência e o mercado o campo da virtuosidade.

Para ele, "a imensa maioria das coisas pode ser feita melhor pela iniciativa privada, restando ao governo poucas funções que the cabem, e que ele deveria cuidar com todo o esmero.". Constantino não consegue perceber e prestar contas da profundidade do problema, que envolve uma dimensão de desigualdade estrutural na distribuição do poder, dos bens econômicos e culturais, inclusive, chega a sugerir que a prisão e o crime não são áreas de importância para o governo. 
Há uma contradição tipicamente liberal a ser percebida nesse tipo de discurso: o Estado Social é demonizado quando existe, exigindo praticamente sua extinção; e o estado penal, por sua vez, também é demonizado, mas neste caso, por sua inexistência ou ineficácia, demandando seu aumento. Dornelles faz uma observação interessante a respeito desta questão:

\begin{abstract}
(...) afastar a preocupação com as condições macroeconômicas do modelo de desenvolvimento desigual, excludente e concentrador, e das condições históricas da exclusão, marginalização, e injustiça social, é tentar responsabilizar as próprias classes subalternas, menos favorecidas, pelos conflitos sociais e a fronteira que se estabeleceu na sociedade brasileira entre os mais privilegiados e os muito despossuídos (DORNELLES, 2003, p. 14)
\end{abstract}

No Brasil, onde há enorme desigualdade social velada, mascarada principalmente pela ideologia meritocrática - como, por exemplo, a ideia de que todos nós estamos igualmente submetidos ao controle e sujeitos da mesma maneira à prisão, isto é, o corolário mais diretamente açulado é o fato de que nem todos os indivíduos estão sujeitos da mesma forma ao controle social - o que Michel Misse especificou e deu contornos mais acentuados chamando de "sujeição criminal" (MISSE, 2010, p. 15) - é preciso se questionar quais, ou melhor, quem são os alvos do estado penal, do presídio e porque são? Torna-se relevante compreender a quem serve este "inferno" e quem é servido por ele. Isso porque o controle não está apartado do mundo social ou das relações de poder, todavia essa seja uma ideologia necessária ao seu próprio funcionamento incluindo sua legitimação.

A prisão não é um destino democrático - ela é reservada a alguns e demonstra o apartheid social que vive o Brasil. A prisão tem sua clientela especial: uma classe inteira de indivíduos precarizados, "antissociais", perigosos, ameaçadores, de pessoas marginalizadas. Quando alguém que não pertence a essa clientela, ou melhor, a esta identidade social, é preso, há uma enormidade de estranhamentos, ou seja, é tão incomum e insólito que é digno de ser enunciado, ainda com aplausos de que a "justiça acontece".

Isso não quer dizer que esta clientela especial seja maior alvo do controle 
porque pratica mais crimes, isto é, que devido à exclusão social destes indivíduos eles são levados ou fadados a praticarem crimes - como se o crime fosse produto da pobreza ou da exclusão [todas as classes cometem crimes, inclusive os incluídos, entretanto, somente uma classe é punida]. Isso quer dizer que há uma assimetria na distribuição do poder e que o controle se reproduz dentro desse universo.

Quando se coloca em pauta a demonização da prisão feita às vezes e as vias do estado neoliberal, queremos demonstrar que esse argumento não visa humanizar a prisão, mas torná-la imperceptível do ponto de vista da hipertrofia do estado penal, no qual, a exclusão é o que está em causa. Em "O lugar da prisão na nova administração da pobreza" (2008), Loïc Wacquant diz que o acionamento da luta contra o crime serviu tão somente como pretexto e trampolim para uma reformulação do perímetro e das funções do Estado, que resultou no enxugamento do seu componente de welfare. O complexo penitenciário ganhou um lugar central como instrumento para a administração da pobreza, dos perigosos e perturbadores.

A parcialidade do controle não reside simplesmente no fato de que seus operadores estão pré-dispostos a julgar a causa, mas justamente o oposto, a causa está predisposta ao julgamento: a polícia, a justiça e demais instituições naturalizam o controle ${ }^{9} \mathrm{e}$, mais do que isso, são impelidos a "garantir" a ordem social contra os considerados "perigosos", "violentos", "criminosos", etc. ${ }^{10}$. Assim, atuam como instrumento reprodutor e garantidor desse processo, esquecendo-se de sua gênese assimétrica em desfavor dos pobres. Nesse sentido, entendemos

9 Para Dornelles, ao ser naturalizado, o controle social se torna aparentemente neutro, justificando como natural e normal a desigualdade social. (DORNELLES, 2003: p. 24)

10 Segundo Foucault (2003: p. 85), a grande noção da criminologia e da penalidade em fins do século XIX foi a escandalosa noção, em termos de teoria penal, de periculosidade. A noção de periculosidade significa que o indivíduo deve ser considerado pela sociedade ao nível de suas virtualidades e não ao nível de seus atos; não ao nível das infrações efetivas a uma lei efetiva, mas das virtualidades de comportamento que elas representam. É também o que o criminologista David Garland chamou atenção em "A cultura do controle: crime e ordem social na sociedade contemporânea": "o criminoso é repensado de forma cada vez mais abstrata, mais estereotipada: cada vez mais uma imagem projetada em vez da pessoa real." (2008: p. 383). 
que é um engano dizer que a polícia ou a justiça tende criminalizar determinados indivíduos, como muitos afirmam, porque seria como considerá-los o próprio fator de criminalização, enquanto na verdade, ela atuam como garantidora desse processo (RODRIGUES, 2013, p.40, 41).

A prisão privada, neste caso, não é a responsável pela criminalização da pobreza, mas ao tornar o preso uma espécie de "mercadoria", cercada de metas. O mercado se ocupa de inverter a lógica questionadora da prisão - e aí podemos perceber que a crítica também é utilizada para minimizar o estado em termos sociais, e aumentá-lo penalmente para os próprios indivíduos que carecem de seu amparo. A prisão privada não é a causa da assimetria do poder ou do controle social, mas opera em uma relação de confirmação dessa própria configuração, porque mais limpo, mais controlador e aparentemente mais humano, o presídio privado é aceito e mais que isso, atinge certa inexorabilidade.

\section{VIGILÂNCIA E CONTROLE NO COMPLEXO PRISIONAL}

O complexo prisional inaugurado, na intenção de aumentar o controle, conta com um aparato tecnológico particularmente grandioso, incluindo aparelhos de segurança e revista na entrada, um sistema de sensoriamento de presença, portas, banho e iluminação automatizados. Cada preso tem sua ficha detalhada, não só criminal, mas de relações de parentesco, doenças e outras informações. No complexo, existem mais de 1.240 câmeras de segurança espalhadas por todo prédio; e duas torres centrais são responsáveis pelo monitoramento e controle de grande parte do sistema. Há um controle disciplinar rigoroso e sistematizado: a água do banho, por exemplo, é programada para terminar em três minutos. Além disso, os presos estão sujeitos a diversas inspeções, a trabalho diário e outros serviços.

Essa questão, o aumento da vigilância e do controle, principalmente, na prisão tem relação direta com uma proposição teórica que não poderíamos desconsiderar chamada panoptismo. Panóptico é um termo cunhado pelo filósofo 
Jeremy Bentham no final do século XVIII, utilizado para refrenciar um mecanismo arquitetural onde haja distribuição de corpos em diversificadas superfícies. Entretanto, foi Foucault quem desenvolveu e sistematizou uma teoria do panóptico alicerçada a questão da dominação e da disciplina.

Segundo Foucault, o panótico "é uma tecnologia de poder apropriada para resolver os problema de vigilância (...) que permite exercer muito facilmente $o$ poder"(FOUCAULT, 1984, P.211), tendo como objetivo induzir no detido um estado consciente e permanente de visibilidade que assegura o funcionamento autoritário do poder. Assim, a vigilância é pensada em termos permanentes nos seus efeitos. Ou seja, o panóptico é a organização do espaço de modo que permite a quem ocupa uma posição de controle ver, sem ser visto: "o Panóptico é uma maquina de dissociar o par ver-ser visto: no anel periférico, e se é totalmente visto, sem nunca ver; na torre central, vê-se tudo, sem nunca ser visto" (FOUCAULT, 2004, p. 167). Tais instrumentos, tem como pressuposto o fato de que o crime, bem como fugas, desvios, tem conexão com a desvigilância e ao mesmo tempo com a oportunidade.

Entretanto, aqui se faz necessário acrescentar uma ponderação acerca da seletividade do controle e da vigilância, é o que Wacquant chamou de social panóptico [e preferimos chamar de panóptico seletivo]. Segundo ele, há uma supervisão cada vez mais punitiva sobre os pobres, mesmo dentro do estado social e dos programas sociais [inclusive essa integração entre os programas de proteção e assistência ainda existentes e o controle dessas populações acontece cada vez mais de modo sofisticado (WACQUANT, 1999, p.80)].

Nesse sentido, o complexo prisional Ribeirão das Neves, que reproduz a seletividade do controle penal, foi feito pensando o controle mais rigoroso possível - e o isolamento total de indivíduos que são mandados para lá. Sua estrutura, a partir do método panóptico de vigilância, condensa um forte aparato tecnológico, disciplina e separação. $O$ detento é controlado 24 horas, não há espaço para privacidade, intimidade ou momento em que "o olho pisca" [como Lyon metaforicamente observou em referência ao termo que dá título a sua obra "O olho 
eletrônico"]. Esse montante é importante e nos ajuda a compreender o Complexo Prisional Ribeirão das Neves porque nos encaminha para um debate sobre a singular relação entre crime, controle, disciplina e tecnologia, no qual Michel Foucault tem uma das primeiras e mais importantes contribuições ${ }^{11}$.

\subsection{CAPILAR AUMENTO DO CONTROLE}

Em Vigiar e Punir, Foucault mostra que com o desaparecimento dos suplícios, houve uma nova estratégia para o remanejamento do poder de punir, de acordo com modalidades que o tornam mais regular, mais eficaz, mais constante e mais bem detalhado em seus efeitos (FOUCAULT, 2004, p.101). Assegurando, com isso, uma melhor distribuição, mais velada e mais forte da punição: o indivíduo não seria mais chicoteado pelo feitor ou pelo carrasco a mando, respectivamente do senhor e do rei, mas por toda população a mando de "ninguém". O poder, então se torna algo que não está centralizado unitário ou global. Além disso, nesta forma de pensamento o poder assume formas díspares, atravessadas, heterogêneas em constante transformação; é impessoal, ou seja, não é dominado pelo indivíduo, mas usado por este. O poder é capilar, molecular, opaco, e se manifesta através de detalhes e pequenas coisas, até atos triviais. Desta forma, torna-se impossível pensar o controle social e a prisão sem que se discuta o poder.

O fim do suplício e as transformações que seguiram a nova economia do poder de punir merecem grande destaque: o aparecimento de uma nova concepção filosófica, principalmente a partir do iluminismo e das revoluções liberais, bem como as novas teorias sobre o direito, transformaram a tortura e a morte em público de espetáculo em ato de repúdio e condenado pela maior parte da população. Tal transformação, embora pareça uma forma menos cruel e mais

11 Segundo Dornelles (Op. Cit: p.23), Foucault, embora abstraindo o papel do estado, com o conceito de sociedade disciplinar e a noção de planificação social e controle socoal, analisa como a sociedade ocidental contemporênea, de corte urbano-industrial, elaborou mecanismos de controle altamente sofisticados. 
generosa do estado punitivo, não é pensada e articulada a partir do intento humanitário, mas justamente ao contrário. A nova economia de punir é dissipada por toda população; a condenação e a pena acontecem de modo mais velado e sutil e, portanto, muito mais difícil de ser contestada.

O intento da prisão construída e administrada pelo setor privado, com tamanho aparato tecnológico, repressivo, controlador, não é torná-la um destino democrático, que respeite suficientemente os direitos humanos a ponto de servir para qualquer um, mas torná-la um instrumento de controle imperceptível, disciplinatório das classes perigosas, fazendo também com que o controle não mais seja percebido como desigual e assimétrico.

Como iniciamos dizendo, o suplício e a barbárie nas prisões brasileiras são constantemente enfatizados em jornais, revistas e mesmo no debate intelectual: há diversas monografias, dissertações e teses sobre a situação do cárcere e direitos humanos. Este não é o problema, mas quando se utiliza deste discurso, sem perceber a lógica que se constitui diante da segmentação de classes no Brasil, da assimetria do poder, do controle social e penal, buscando questionar a situação da prisão justamente para aumentar ainda mais o estado penal, onde sequer ele é social, produz-se assim, um enorme bloqueio simbólico onde a punição e a prisão se destinam somente à uma classe.

. O Complexo Prisional Ribeirão das Neves ganha força porque transforma, o "espetáculo das punições", não mais desejadas, em algo sofisticado e econômico, do suplício ao aprisionamento da alma no próprio corpo, a morte social do indivíduo. Em primeiro porque elimina em grande escala a possibilidade de fuga, fazendo com que a prisão seja uma garantia e não a possibilidade do isolamento. Outra porque a torna mais "invisível", cuja percepção é dada a redução do derramamento de sangue, o "fim" da barbárie, do suplício, dos motins. 


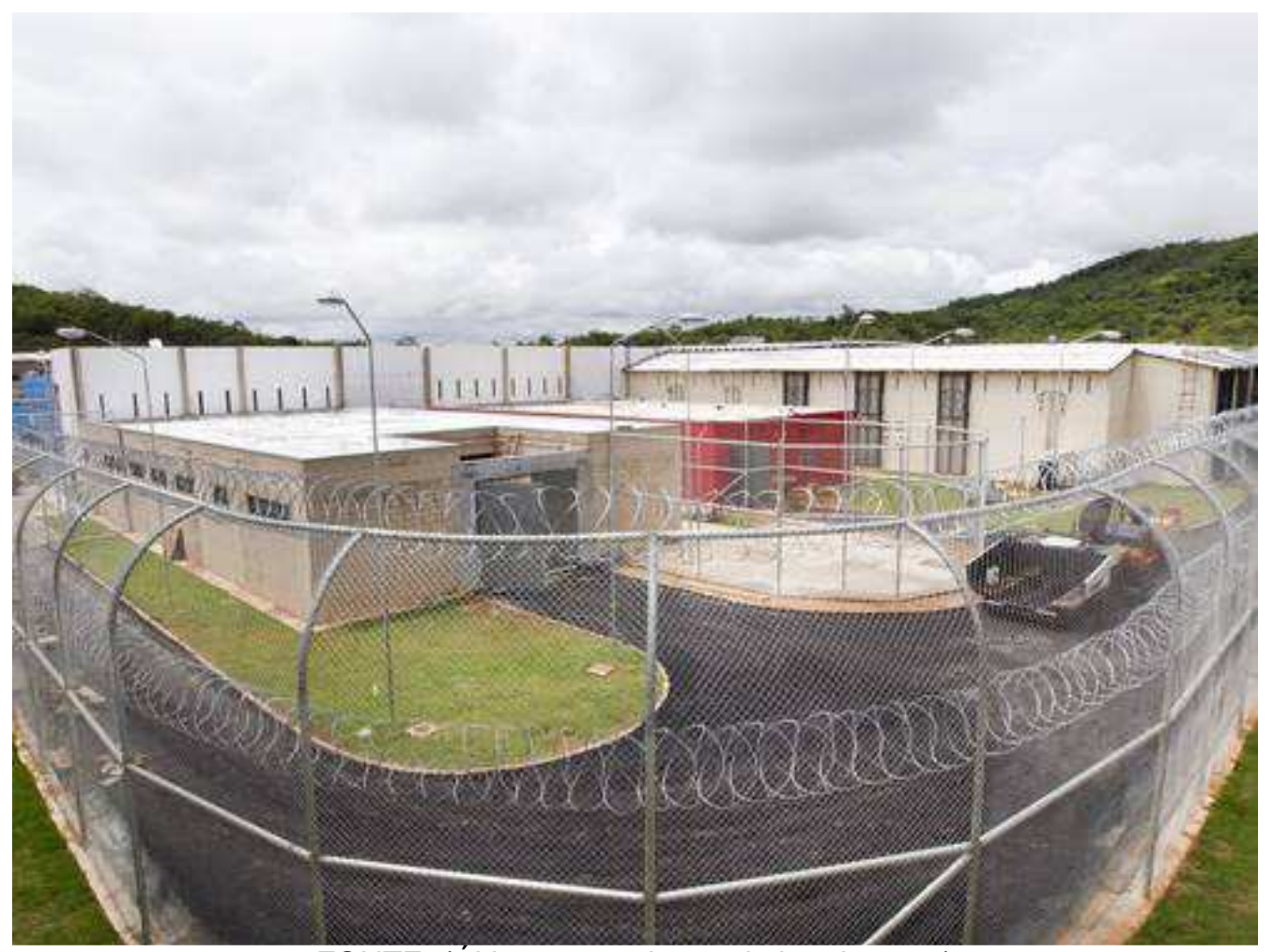

FONTE: (Último segundo, 18 de jan de 2013)

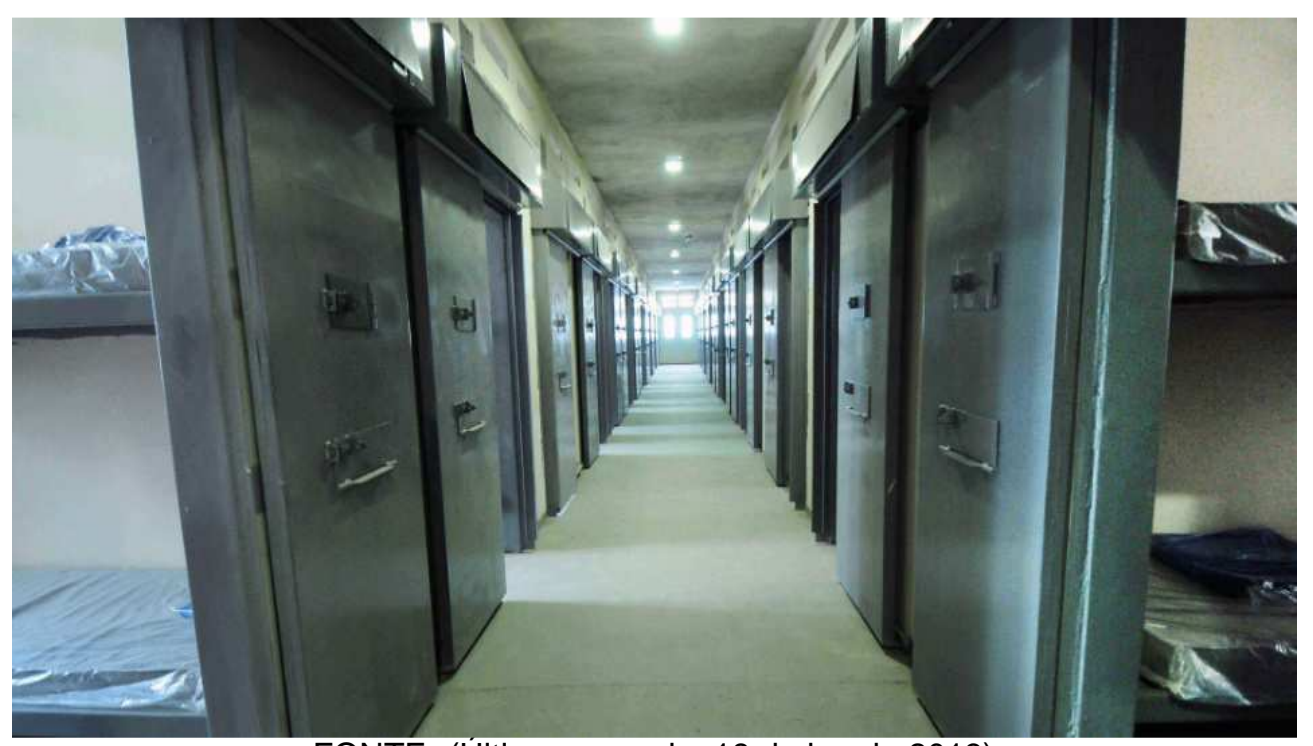

FONTE: (Último segundo, 18 de jan de 2013)

\section{O VELHO E O NOVO}

Em que medida o "novo modelo de prisão", conforme anunciou o 
Governador do estado de Minas Gerais, é novo? Quais são as diferenças desta prisão e das demais, as demonizadas? Tais questões são chave para entender o que estamos propondo. O presídio construído e administrado pela iniciativa privada não é causa do estado mais penal, tampouco do aumento do encarceramento, o problema não reside aí. A princípio, o presídio agrada, principalmente, por ser mais higiênico e organizado; ele é atrativo e, portanto, passa não só a não ser questionado, mas tomado como eficaz e símbolo de boa gestão, como fez a Revista Veja, na reportagem "É exceção, mas deveria ser regra".

O modelo de controle do complexo penitenciário de Ribeirão das Neves é baseado no isolamento e na exclusão - e, assim como das demais prisões - não há uma inversão desta lógica. Todavia, o fortíssimo esquema de vigilância, que coliga tecnologia e disciplina, faz com que no complexo o controle seja alcançado em níveis maiores e em termos mais efetivos: o preso sofre um isolamento maior que nas outras prisões, tudo é padrão e não há espaço para particularidades. Neste caso, também é preciso dizer que o controle gera lucro, pois caso ocorra uma rebelião e, brigas, a concessionária perde metas e deixa de ganhar dinheiro.

O modelo continua sendo baseado na contenção de um segmento marginalizado da população, ao invés da ressocialização. O crime e a violência da mesma forma são tratados somente como problemas de segurança e, agora, como algo legalmente lucrativo. O perigo reside na legitimação do problema enquanto solução, de modo que, o estado penal - agora nem tão estado assim, quase um "mercado penal" - seja mascarado e garantido pelas vias neoliberais. A "nova prisão" é tão infernal quanto à "velha prisão", entretanto é mais pirotécnica. Não há mudança no método ou na ideologia punitiva, mas sim intensificação. É como se o inferno se disfarçasse de céu, para ser louvado e legitimado por um discurso "pseudo-humanitário", mas que é visto como bom porque isola e consegue isolar quem deve ser excluído. 


\section{CONCLUSÃO}

A segunda metade do Século $X X$ trouxe grandes transformações, sobretudo, o pós-guerra: o neoliberalismo, a decadência do estado de Bem-Estar Social, o aumento do estado penal, o advento de diversas tecnologias, entre outras que aqui mencionamos. A prisão, não pode ser entendida fora deste contexto, principalmente, o complexo prisional de Ribeirão das Neves.

Neste sentido, tem-se observado uma demonização da prisão: o cárcere não ressocializa, as condições são desumanas, a prisão é um inferno. Essa sindicância, embora aparentemente conteste a ordem estabelecida, serve ao estado penal ou ao "mercado penal" na medida em que clama por mais controle, mais rigor e mais isolamento e ao mercado, na medida em que demoniza a ineficiência do estado em conter os "marginais" e os "bandidos".

O complexo apresentado como "novo modelo", na verdade, não inverte a ideologia punitiva do estado neoliberal, mais do que isso, ele utiliza desta lógica para engendrar lucro. O crime, a indisciplina e o desvio geram lucro, o controle e a disciplina geram lucro. Embora o complexo prisional privado não seja a causa principal, mas uma consequência secundária e incidental do desenvolvimento hipertrófico do aparato penal, acaba por estimulá-lo, como um fator de retroalimentação, como aumento de controle. De modo que não é começo e muito menos o colapso do inferno, o maior problema se deve ao fato de que o complexo tem o potencial de ocasionar a legitimação da prisão como instituição de um aparente sucesso: entretanto a intensificação do controle não estabelece uma sinônima com "o fim do inferno". Com isso, o estado penal passa a ser menos percebido ou percebido como justo, humanitário e ressocializante.

Não se trata de um problema de comparação entre indicadores entre presídios públicos e privados, se há menos rebeliões, quantos reincidem, etc. Daí porque o presídio se pauta no controle e na contenção de um segmento populacional marginalizado. Em segundo, porque ele trata o mercado como solução, como o campo da virtude. A privatização da prisão mascara o problema 
do controle e do crime, aumentando a sensação de que ambos estão sendo resolvidos, por outro lado, diminui o ímpeto e a força das alternativas para melhorar o sistema de ressocialização e prevenção do crime.

\section{BIBLIOGAFIA}

CARVALHO FILHO, Luiz Francisco. A prisão. São Paulo: Publifolha, 2002.

CONSTANTINO, Rodrigo. Prisão privada. São Paulo: Veja, Ed. Abril. 10 de ago 2013. Acesso em 19 de set de 2013; disponível em http://veja.abril.com.br/blog/rodrigo-constantino/privatizacao/prisao-privada/

DORNELLES, João Ricardo. Conflito e segurança (entre pombos e falcões). Rio de Janeiro: Lumen Juris, 2003.

FOUCAULT, Michel. As palavras e as coisas: uma arqueologia das ciências humanas. 8.ed. São Paulo: Martins Fontes, 2000.

2003.

As verdades e as formas jurídicas. $3^{\text {a }}$ Ed. Rio de Janeiro: Nau Editora;

Vigiar e Punir. Petrópolis: Vozes. 2004.

Microfísica do Poder, 1984.

FRANCISCO NETO, José. Presídios privatizados invadirão o país, afirma exdiretora do sistema penitenciário do Rj. São Paulo: Brasil de Fato 05 jan 2013. Disponível em: <http://www.brasildefato.com.br/node/11852> Acesso em: 10 de nov 2013.

GARLAND, David. A cultura do controle: crime e ordem social na sociedade contemporânea in Coleção Pensamento Criminológico. Rio de Janeiro: Editora Revan, 2008.

LYON, David. The Eletronic Eye: The Rise of Surveillance Society. United States: University of Mimnesota Press, 1994.

MISSE, Michel. Crime, sujeito e sujeição criminal: aspectos de uma contribuição analítica sobre a categoria "bandido". São Paulo: Lua Nova, 2010.

MOREIRA, Pedro. Minas inaugura polêmico modelo de prisão no país. Porto Alegre: Zero Hora, 17 de jan de 2013. Acesso em 16 de set de 2013; disponível 
em http://zerohora.clicrbs.com.br/rs/policia/noticia/2013/01/minas-inaugurapolemico-modelo-de-prisao-no-pais-4014541.html.

ULTIMO SEGUNDO. Primeira penitenciária privada do país começa a funcionar em minas gerais. portal ig. 18 de jan 2013. acesso em 19 de set de 2013; disponível em: http://ultimosegundo.ig.com.br/brasil/mg/2013-01-

18/primeira-penitenciaria-privada-do-pais-comeca-a-funcionar-em-minas-

gerais.html

RODRIGUES, Igor de Souza. O ser bandido. Juiz de Fora: Instituto de Ciências Humanas - Universidade Federal de Juiz de Fora, 2013.

SOUZA, Jessé. A ralé brasileira: quem é e como vive. Belo Horizonte: Editora UFMG, 2011.

WACQUANT, Loïc. As prisões da miséria.Rio de Janeiro: Jorge Zahar, 1999. O lugar da prisão na nova administração da pobreza, São Paulo:

Novos estud. - CEBRAP n.80, Mar. 2008. 